This item was submitted to Loughborough's Research Repository by the author.

Items in Figshare are protected by copyright, with all rights reserved, unless otherwise indicated.

\title{
An experimental study of nonlinear behaviour of capacitance in graphene/carbon nanotube hybrid films
}

PLEASE CITE THE PUBLISHED VERSION

http://dx.doi.org/10.1051/epjap/2016160006

PUBLISHER

EDP Sciences

VERSION

AM (Accepted Manuscript)

\section{PUBLISHER STATEMENT}

This work is made available according to the conditions of the Creative Commons Attribution-NonCommercialNoDerivatives 4.0 International (CC BY-NC-ND 4.0) licence. Full details of this licence are available at: https://creativecommons.org/licenses/by-nc-nd/4.0/

\section{LICENCE}

CC BY-NC-ND 4.0

\section{REPOSITORY RECORD}

Alsawafi, Suaad, Xiao Wang, Jie Jin, and Mo Song. 2016. "An Experimental Study of Nonlinear Behaviour of Capacitance in Graphene/carbon Nanotube Hybrid Films”. figshare. https://hdl.handle.net/2134/21390. 
An experimental study of nonlinear behaviour of capacitance in graphene/carbon nanotube hybrid films

\author{
Suaad Alsawafi, Xiao Wang, Jie Jin and Mo Song* \\ Department of Materials, Loughborough University \\ Loughborough LE11 3TU, UK \\ $\underline{\text { m.song@,lboro.ac.uk }}$
}

\begin{abstract}
Graphene $(\mathrm{G})$ and graphene oxide (GO)/carbon nanotubes (CNTs) hybrid films were fabricated as high performance electrode materials by a simple water solution casting method with different contents of single-wall CNT (SWCNT), multi wall CNT (MWCNT) and multi wall CNT with hydroxyl group (MWCNT-OH). The films with MWCNTs showed a layered, interconnected and well entangled structure at nano-scale. With increasing CNT contents, the capacitance of the G/MWCNT and GO/MWCNT films raised almost linearly and their resistance reduced. G/SWCNT and GO/SWCNT films did not form layered structures leading to a very low capacitance. Nonlinear behaviour of the capacitance with voltage has been observed in the G/MWCNT and GO/MWCNT hybrid films. The length and thickness of the hybrid film have significant influences on the capacitance. The capacitance and conductivity increase with increasing the thickness and decrease with increasing the length of the hybrid films. For the application of graphene/CNT hybrid films as electrodes, these characters could be taken into account.
\end{abstract}

Keywords: Graphene, carbon nanotube, conductivity, capacitance 


\section{INTRODUCATION}

Graphene based materials have been considered as the era subject in most of currently researches since graphene discovery [1-6]. It plays an essential role beside the carbon nanotubes (CNTs) in the nanomaterial's world due to their outstanding mechanical, thermal, optical and electrical properties [7-11], which make it suitable for wide applications such as field-effect transistors [12], batteries [13], solar cells [14], fuel cells [15], actuators [16, 17], and supercapacitors [18-21].

Recently, hybrid nanostructures have received a great deal of attention in different studies which focused on graphene based material hybrid films. The functionalised hybrid material can complement the deficiencies of pure graphene films [22-24]. Up to now, indium tin oxide (ITO) has usually been used as a transparent electrode (TE) in solar cells, organic light emitting diode panels and touch panels because of its high optical transparency and low sheet resistance. However, sustainability and price concerns give the need to be replaced for new transparent conductive materials with a high mechanical flexible material but low cost one [25]. Thus, there are daily efforts to fabricate transparent, conductive and flexible graphenebased material electrodes (TEs) and field effect transistors electrodes (FETs) [18-21, 26-40]. For example, graphene and silver or copper nanowire hybrid films [41-45] attracted enormous interest to been investigated as possible replacements in particular transparent and flexible electrodes $[25,40]$. Xu et al. [46] reported the use of graphene/silver nanowire hybrid films as electrodes for transparent and flexible acoustic device, in which the grain boundaries in graphene are bridged by AgNWs and the empty spaces in AgNWs network are filled by graphene. The presented properties are better than ITO with a sheet resistances as low as $16 \Omega / \mathrm{m}$ and a high optical transparency of $91.1 \%$ at $550 \mathrm{~nm}$. It also showed excellent mechanical flexibility and stability against thermal oxidation. Iskandar et al. [40] claimed how reduced graphene oxide/copper nanowire hybrid films can be used as transparent electrodes in Prussian blue based electrochromic apparatus. Their performance was with improved adhesion, electrical conductivity, oxidation resistance and stability in harsh environments which makes them better than the pure metal nanowires.

On the other hand, graphene and CNTs hybrid films have been developed with excellent electronic properties to work as electrodes. Kim et al. [25] reported the high performance TEs and FETs by using the single wall CNTs and graphene hybrid films. They have found that the sheet resistance reached $300 \Omega / \mathrm{m}$ with $96.4 \%$ transparency. Very recently, a simple and 
practical solution-casting method has been used to prepare the graphene-based electrodes $[22$, $23,32,34,37,47]$.

All studies have focused on the development of graphene/CNT hybrid films to make excellent willing materials which are utilized in different electrical devices. However, the influence of microstructure of the hybrid film on its electrical properties such as conductivity, capacitance and the change of the values with frequency and voltage has never been reported. For the applications of graphene based hybrid materials as electrodes or electrical devices, perhaps, the influences could be important, which must be address clearly. In this study, the electrical properties of the graphene/CNT hybrid films such as conductivity and specific capacitance were assessed with changing voltage, frequency, the length and thickness of the hybrid films, which will provide useful information about the electrical performance of graphene-based hybrid films as electrodes.

\section{EXPERIMENTAL DETAILS}

\subsection{Materials}

Expandable graphite (EG), which is the natural flake graphite that was treated chemically with sulphuric acid to be expandable, was purchased from China Qing Dao Graphite Company. Single-wailed carbon nanotubes (SWCNTs), and multi-walled CNTs (MWCNTs), and MWCNTs-OH (with hydroxyl groups 3-5wt\%) were purchased from Chengdu Institute of Organic Chemistry, Chinese Academy of Sciences.

\subsection{Preparation of graphene and graphene oxide}

The graphene used was produced by mechnochemical method [48] from the expandable graphite in the lab. The preparation of graphene is as follows. Expandable graphite was mixed with powder melamine in volume ratios of 1:1. The mixture was dispensed into deionised water to make a solution with a concentration of $1 \mathrm{~g} / 100 \mathrm{ml}$. The solution was then heated up to and kept at $80^{\circ} \mathrm{C}$ for 1 hour with constant stirring, to allow the melamine to fully penetrate and expand the graphite galleries. After this, the solution was filtrated and dried at $80^{\circ} \mathrm{C}$. The dried mixture then underwent ball-milling to initially exfoliate the graphite layers, and then dispersed in de-ionised water and underwent further exfoliation with sonication for 1 hour (Fisher Scientific Sonic Dismembrator Model 500, 300 W). Hot water was used to repeatedly wash the mixture to remove the melamine. 
In order to prepare graphene oxide (GO) $2.5 \mathrm{~g}$ of the expandable was mixed with $57.5 \mathrm{ml}$ of concentrated $\mathrm{H}_{2} \mathrm{SO}_{4}$ in an ice bath for 30 minutes (Hummer method [49]). In order to keep the temperature of the mixture below $20^{\circ} \mathrm{C}, \mathrm{KMnO}_{4}$ was added slowly to the mixture. Using a water bath the mixture was then heated to $35 \pm 3^{\circ} \mathrm{C}$ with continuous stirring for $30 \mathrm{~min} .115$ $\mathrm{ml}$ of distilled water was added drop wise into the mixture which increased the temperature of the mixture to $98^{\circ} \mathrm{C}$. The mixture was stirred for 15 minutes at this temperature. Later 350 $\mathrm{ml}$ of distilled water and $25 \mathrm{ml}$ of $30 \% \mathrm{H}_{2} \mathrm{O}_{2}$ solution were added to terminate the oxidation reaction. Graphite oxide (GO) was collected by filtering and was successively washed with 5\% $\mathrm{HCl}$ aqueous solution. $\mathrm{HCl}$ washing was repeated three times until there was no sulphate detected by $\mathrm{BaCl} 2$ solution. $\mathrm{GO}$ collected from the mixture was dried at $50^{\circ} \mathrm{C}$ in vacuum for one week.

\subsection{Preparation of graphene $(\mathrm{G}) / \mathrm{CNT})$ and graphene oxide (GO)/CNT hybrid thin films}

$\mathrm{G}$ or $\mathrm{GO} /$ distilled water dispersion was obtained via ultrasonic treatment for $30 \mathrm{~min}$ at room temperature. SWCNTs, or MWCNTS, or MWCNTs-OH was also dissolved in distilled water by assistance of ultrasonication for the same time. Then the $\mathrm{G}$ or $\mathrm{GO} /$ distilled water dispersion and SWCNTs, or MWCNTs, or MWCNTs-OH/distilled water dispersion were mixed to make different concentrations by controlling the volume of $G$ or GO. All the mixtures were then treated by ultrasonic separately for another 30min. After this, each mixture was dropped on a cover slip placed in a glass container. The hybrid thin films coated on the cover slips were obtained after drying for 3 days (in vacuum oven for the $3^{\text {rd }}$ day) at $40^{\circ} \mathrm{C}$. The thickness of the films was controlled by the volume of the mixture dropped on the cover slip.

\subsection{Characterization}

Field-emission gun scanning electron microscopy (FEGSEM) (LEO 1530VP instrument) was used to observe the surface and cross-sectional morphology of the hybrid thin films. Transmission electron microscopy (TEM) analysis was conducted using a JEOL 2100 FX instrument. Programmable automatic RCL meter (Fluke PM6306) with SMD tweezers (Fluke PM9540/TWE) was used to measure the resistance and capacitance of the hybrid films by means of scanning voltage $(50 \mathrm{mV}$ to $2 \mathrm{~V})$ and frequency $(50 \mathrm{~Hz}$ to $100 \mathrm{kHz})$. Fluke PM6306 has four terminal sensing points that is used to amount the square resistance of a semiconductor material. This can be done by separating the current and the voltage electrodes which help to eliminate the contribution of wiring impedance and contacting resistance. As a 
constant current is passing through the outer probes, the voltage can be measured through the inner probes. This allows to the electrical impedance measurement of the substrate $\mathrm{R}$ and capacitance. Before this test, all the cover slips were painted by silver at two opposite edges in order to get steady readings. The tweezers were just touching the two painted edges when testing.

X-Ray photoelectron spectroscopy (XPS) analysis of MWCNT-OH and MWCNT films and was performed on a VG ESCALAB 5 (VG Scientific Ltd., England) under $10^{-7}$ Torr vacuum with a AlKa X-Ray source using power of $200 \mathrm{~W}$. 


\section{RESULTS AND DISCUSSION}

Figure 1 shows the cross section SEM images for GO/MWCNTs and GO/MWCNT-OH hybrid films. These SEM images reveal the appearance of tilting layered structure in the thin films. This layered structure is well-arranged in where insulated layers of graphene oxide are filled with conductive CNT in between. It exhibits the information of the support of 2D graphene oxide for MWCNT horizontally. Therefore, the film structure is conserved in a large area. This large contact area between CNTs and GO (the insulators) could be able to store quite a lot of charges in the conductor's layers.
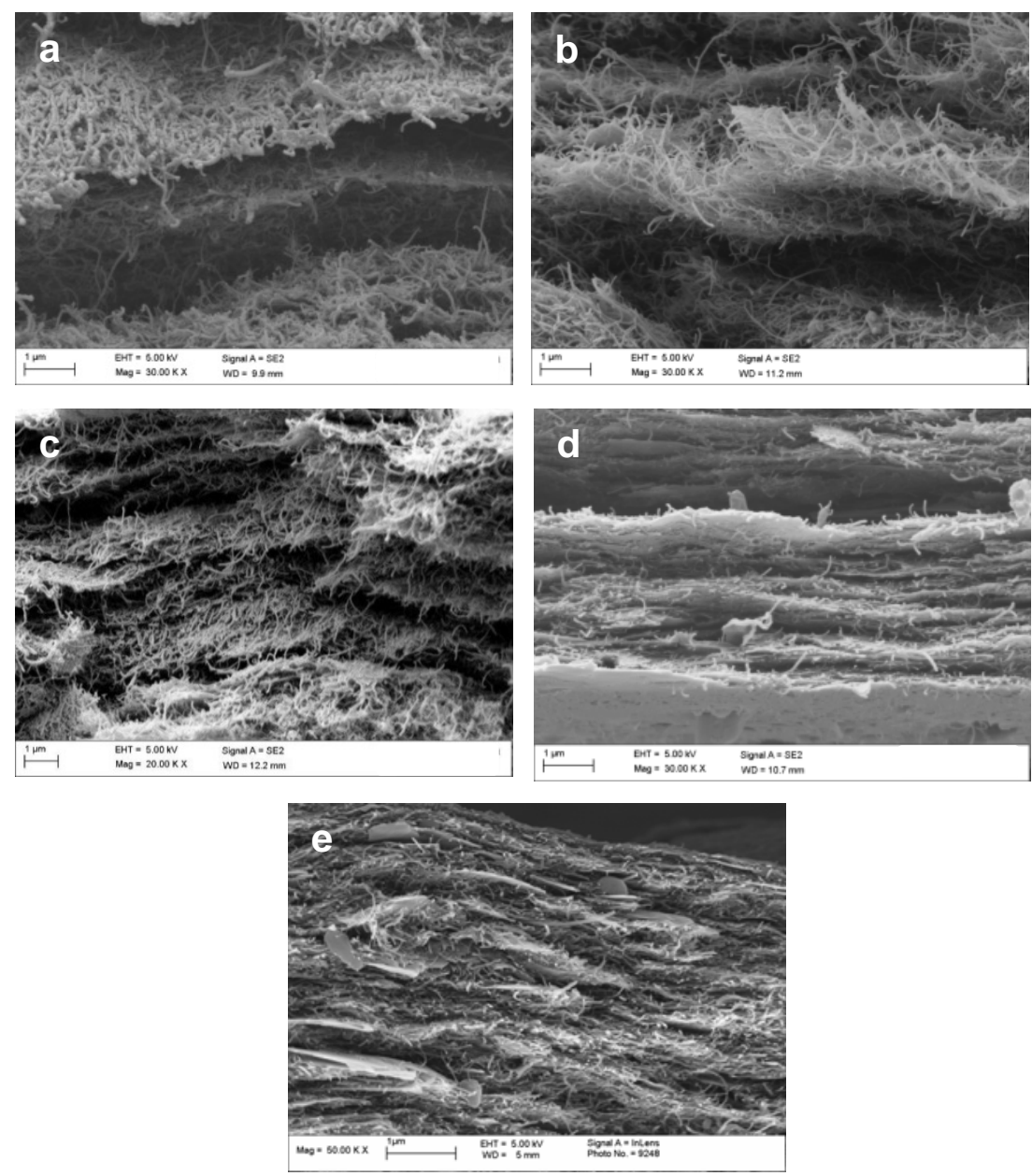

Figure 1: Cross section SEM images of the GO/CNT hybrid films. (a)GO(20wt\%)/ MWCNTs (80wt\%); (b) GO(40wt\%) /MWCNTs (60wt\%)); (c) GO(60wt\%)/MWCNTs (40wt\%); (d)GO(80wt\%)/ MWCNTs (20wt\%); (e) GO (50wt\%)/MWCNT-OH (50wt\%)

Figure 2 shows the SEM images of the surface of the GO/CNT hybrid films. The transparent sheets covered a larger area in these films with increasing GO content which lead to a percolated network. Unlike MWCNTs, Figure 2(f) shows that the networks are not noticeable 
even with $60 \mathrm{Wt} \%$ SWCNTs, which shows a poor percolated network due to the poor dispersion of SWCNTs.
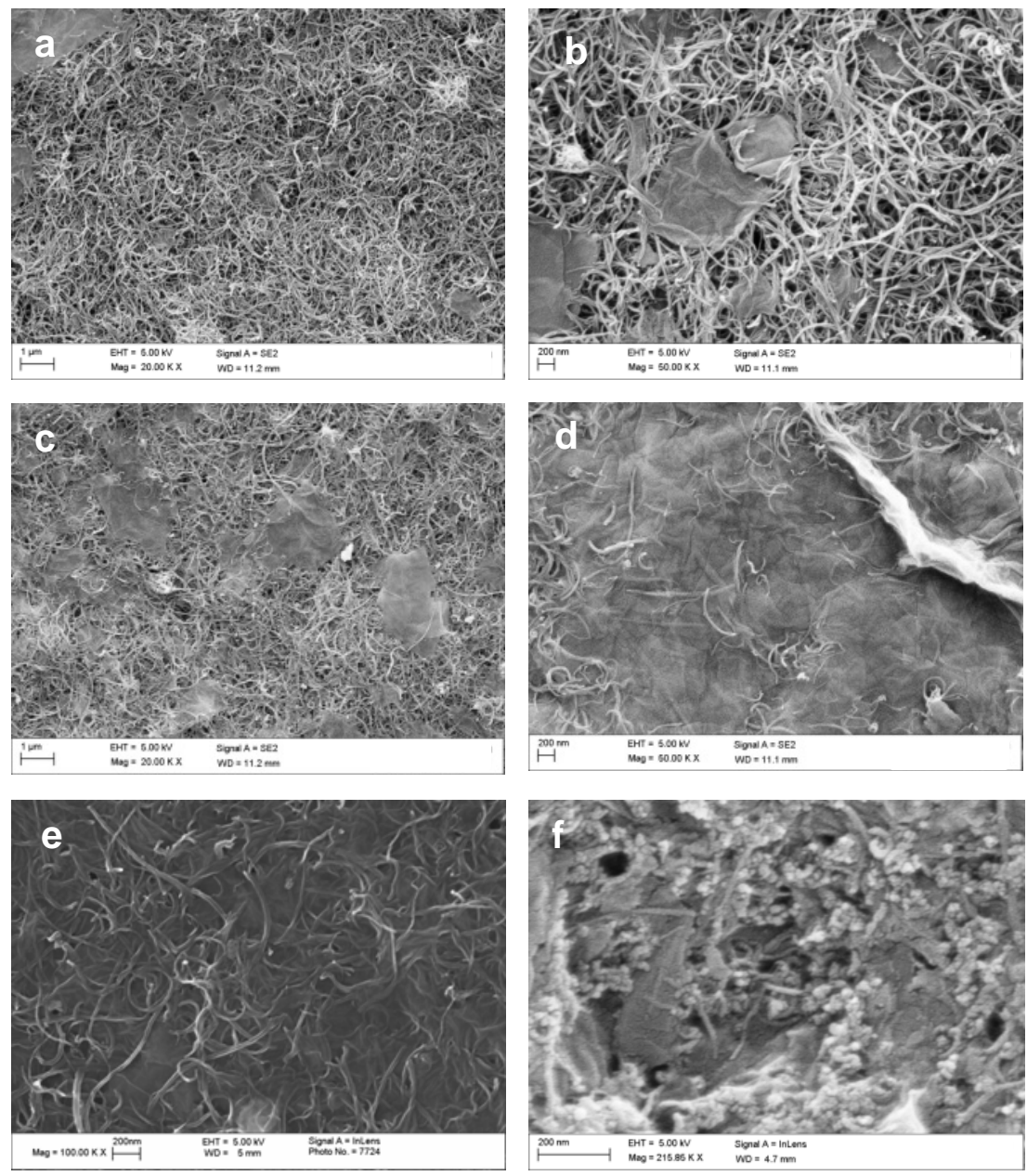

Figure 2: SEM images of the surface of the hybrid films. (a) GO(20wt $\%$ )/MWCNTs (80wt\%); (b) GO(40wt\%)/MWCNTs (60wt\%); (c) GO(60wt\%)/MWCNTs (40wt\%); (d) GO(80wt\%)/MWCNTs(20wt\%); (e) Surface SEM image of GO(wt\%)/MWCNT-OH (50wt\%); (f) GO(40wt\%)/ SWCNTs (60wt $\%)$

Figure 3 shows the SEM images of cross sectional area and the surface of G/CNT hybrid films. The images reveal that the information obtained is similar to that of GO/MWCNT hybrid thin films. However the layered structure in the G/MWCNT system is not well-formed comparing with the GO/MWCNT films. Figure 3 (b-d) shows the surface images in which darker opaque $\mathrm{G}$ sheets covered the CNTs in a small area even with $80 \mathrm{wt} \%$ graphene. The G/SWCNT film (Figure 3e), again, formed a very poor percolated network. 


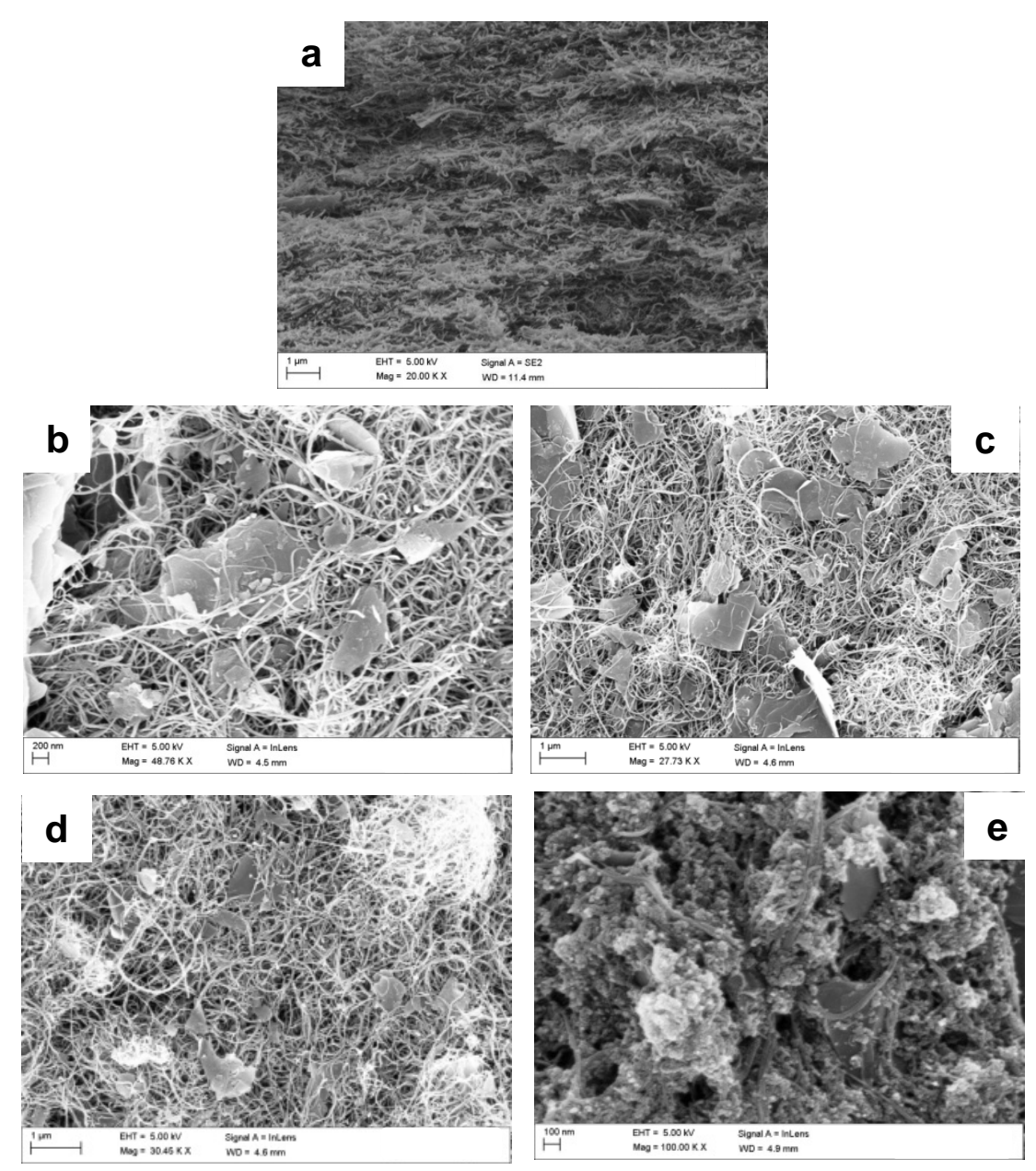

Figure 3: SEM images of the surface of the hybrid films. (a) cross sectional area of $G$ (40wt $\%) /$ MWCNTs (60wt $\%$ ) hybrid film; (b) surface of $\mathrm{G}(20 \mathrm{wt} \%) / \mathrm{MWCNTs}(80 \mathrm{wt} \%)$; (c) surface of G(60wt\%)/MWCNTs (40wt\%); (d) surface of G(80wt $\%) / M W C N T s ~(40 w t \%)$; and (e) surface of G(40wt\%)/SWCNTs $(60 \mathrm{wt} \%)$

Figure 4 shows electrical conductivity against wt.\% CNTs for G/MWCNT and GO/MWCNT hybrid films. In the GO/MWCNT and GO/MWCNT-OH systems, there is a linear relationship of electrical conductivity with CNT content. In the G/MWCNT and G/MWCNT$\mathrm{OH}$ systems, a nonlinear relationship of electrical conductivity with CNT content was found. 

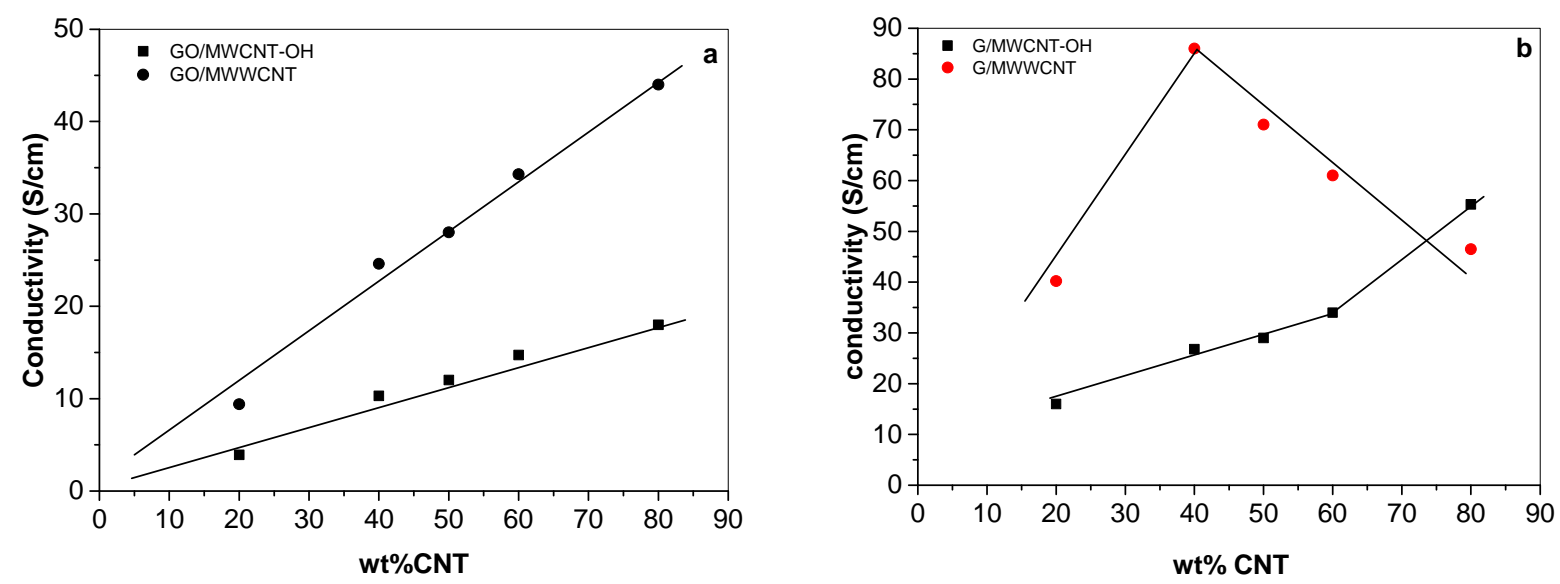

Figure 4: Electrical conductivity versus wt $\%$ CNTs for (a) GO/CNT systems and (b) G/CNT systems

Although both G-based MWCNTs and MWCNTs-OH hybrid films exhibit similar trends, MWCNTs hybrid thin films show a higher conductivity than MWCNTs-OH. This can be explained by changing the electronic property of $\mathrm{CNT}$ as a result of $-\mathrm{OH}$ group presence. This group works as cavity or holes which prevent accumulation of charges by reducing the area and so dropping the final specific capacity. The $-\mathrm{OH}$ groups affect the material resistance as well as the percolated network. The $-\mathrm{OH}$ groups tend to decrease the overall material conductivity by twisting the CNTs and could short the conjugated length. Figure 5 shows XPS results for MWCNTs and MWCNT-OH. The side group's influence should be taken into account in forming a better percolated network.

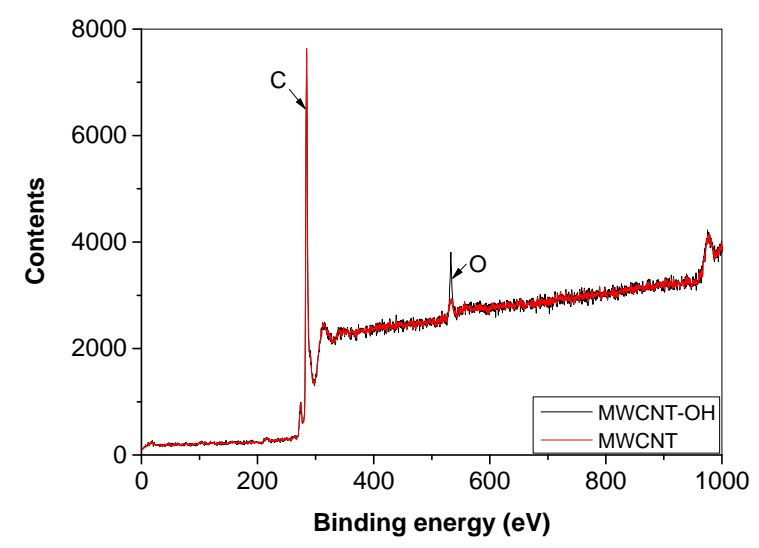

Figure 5: XPS results for MWCNTs and MWCNT-OH

The G/MWCNT hybrid films have a much higher conductivity comparing with the GO/MWCNT due to both G and CNT being conductive materials. However, the conductivity 
of the hybrid films with SWCNTs in comparison to MWCNT systems is much lower due to the poor dispersion of SWCNTs and non-layered structure. As well known, generally, SWCNTs are bundled together and very difficult to form single SWCNT dispersion in solution or in a matrix. Based on these results, it is believed that G/SWCNT or GO/SWCNT systems are not suitable for development of high quality electrodes.

The capacitance with frequency for $\mathrm{G}$ and GO based hybrid films from $0-10000 \mathrm{~Hz}$ at $2 \mathrm{~V}$ was also assessed. Generally, the capacitance was found to decrease down to zero at high frequencies. The highest value of the capacitance was found at about $50 \mathrm{~Hz}$. The capacitance of both G and GO hybrid films decreases rapidly down to zero at about $2000 \mathrm{~Hz}$. This could be because the lower the frequency of the applied voltage, the more time the capacitor needs to be a fully charged. Then it passes with a zero current state before the voltage reverses its polarity and the capacitor start to discharge. When a higher frequency is applied, the capacitor changes from charging to discharging sooner in its charge curve and it remains further from its fully charged state.

The capacitance of the hybrid films against wt $\%$ CNTs at $50 \mathrm{~Hz}$ with $2 \mathrm{~V}$ are shown in Figure 6. There is a linear relation of the maximal capacitance with $w t \%$ MWCNTs in the GO/MWCNT. However, the value reaches to the highest at 40wt\% MWCNTs in the G/MWCNT system and at 60wt\% MWCNT in the G/MWCNT-OH system.
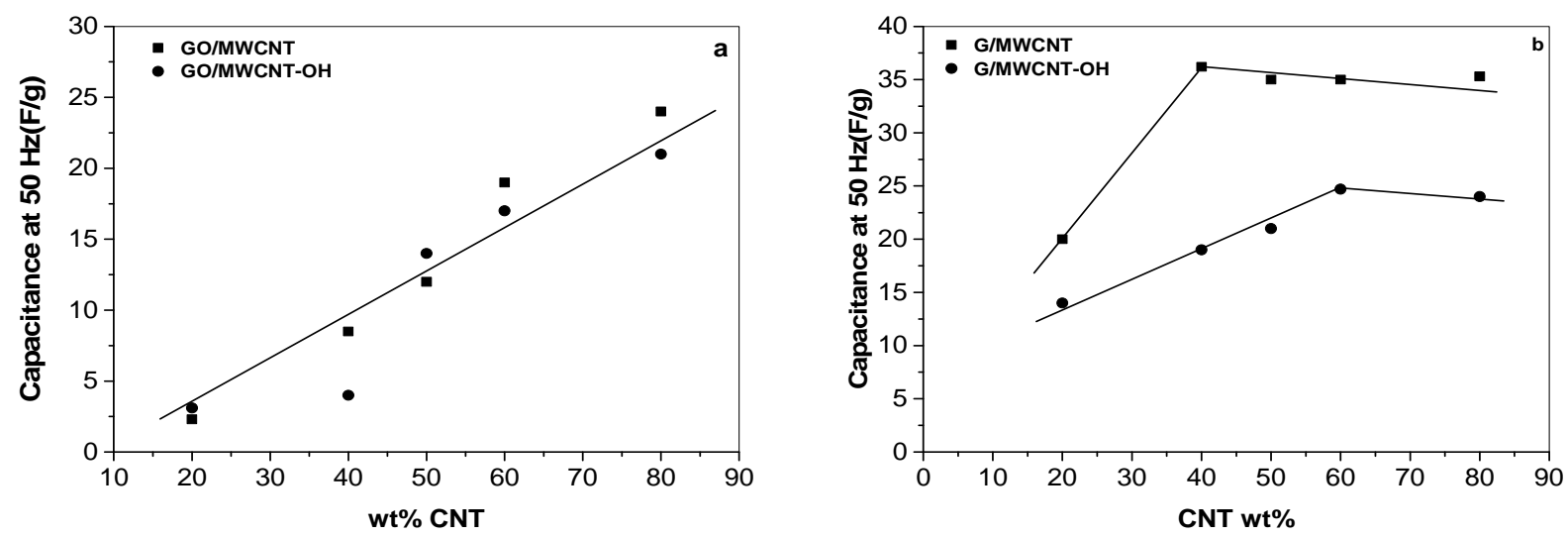

Figure 6: Capacitance at 50Hz against wt $\%$ MWCNTs. (a) GO/MWCNT hybrid films and (b) G/MWCNT hybrid films

Figures 7 and 8 show the plots of capacitance versus scanning voltage from 0 to $2 \mathrm{~V}$ for GO/MWCNT, GO/MWCNT-OH, GO/SWCNT, G/MWCNT, G/MWCNT-OH, G/SWCNT hybrid films with $60 \mathrm{wt} \% \mathrm{CNTs}$, graphene, GO and MWCNT films, respectively at $50 \mathrm{~Hz}$. 

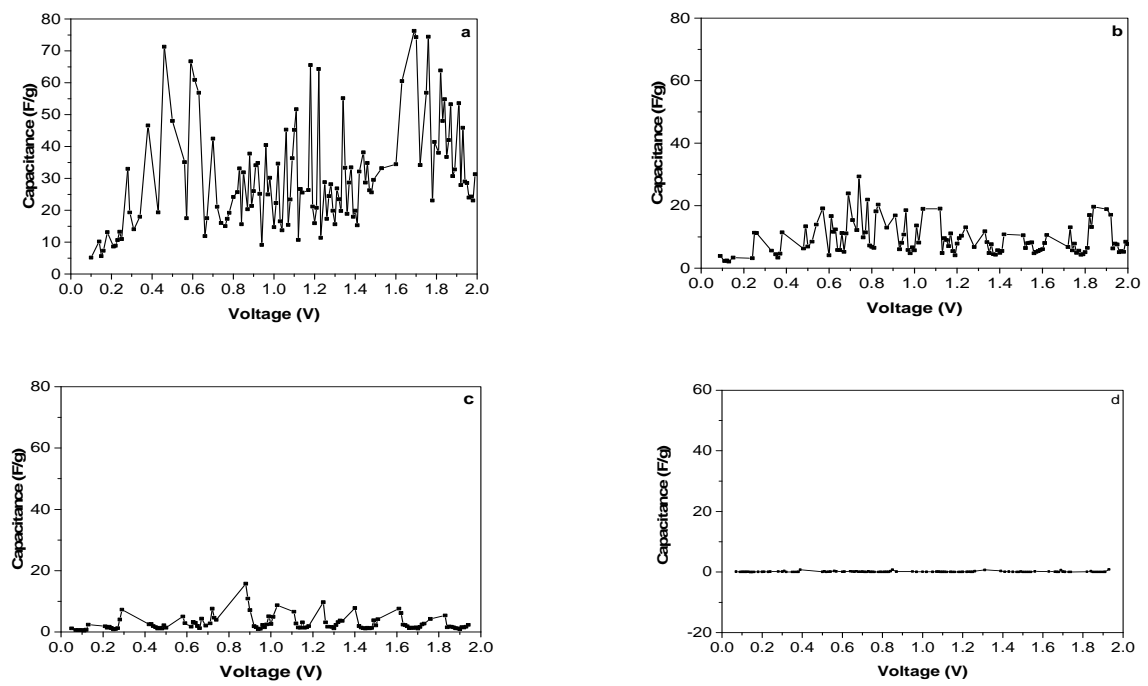

Figure 7: Plots of capacitance versus scanning voltage at $50 \mathrm{~Hz}$. (a) GO (40wt \%)/MWCNT (60wt \%); (b) GO (40wt \%)/MWCNT-OH (60wt\%); (c) GO (40wt \%)/SWCNT (60wt \%); and (d) GO film
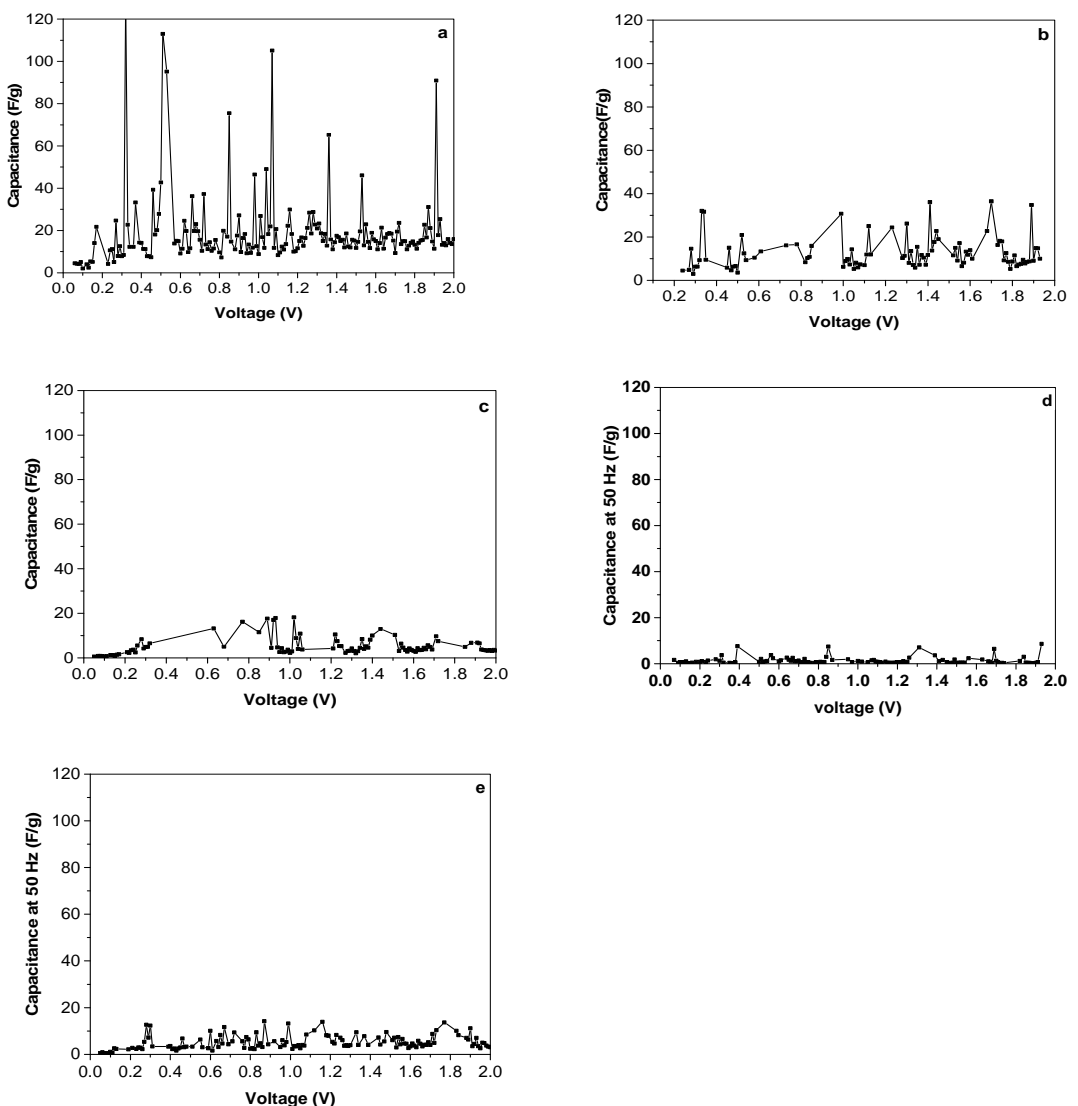

Figure 8: Plots of capacitance versus scanning voltage at $50 \mathrm{~Hz}$. (a) $\mathrm{G}(40 \mathrm{wt} \%) /$ MWCNT(60wt \%); (b) G(40wt \%)/MWCNT-OH (60wt\%); (c) G(40wt \%)/SWCNT (60wt \%) ; (d) MWCNT film; and (e) graphene film 
Results show a non-linear behaviour of the capacitance with voltage in all hybrid films. At some voltages, the capacitance reaches to maximal values (peak) and at some voltages, reaches to minimum values (valley).

It is clear the capacitance is quite dependent of the voltage loaded. It is possible that nanojunctions formed between $\mathrm{G}$ or GO and CNTs when the content of carbon nanotubes was high. The peak values of the capacitance appeared where the junctions are fully exerted at the relevant voltages. The capacitance was found to be higher in G/CNT than in GO/CNT which is not as expected. GO is an insular which can form a capacitor system with the conductive CNT layers. Conversely, $\mathrm{G}$ is a conductive with another CNT conductive material could give a very weak capacitor system. The unexpected results seem that the nanostructure could have significant influences on its performance as electrodes. Generally, the change of the capacitance with voltage indicates that the stability of the G/CNT and GO/CNT hybrid films as electrodes is questionable.

Figure 9 shows the relation of the electrical conductivity and the maximal capacitance with the length and thickness of the hybrid films measured at $50 \mathrm{~Hz}$ and $0.3 \mathrm{~V}$. The results indicate that the length and thickness of the hybrid film have significant influences on the capacitance. The capacitance increases with increasing the thickness of the film and decreases with increasing the length.
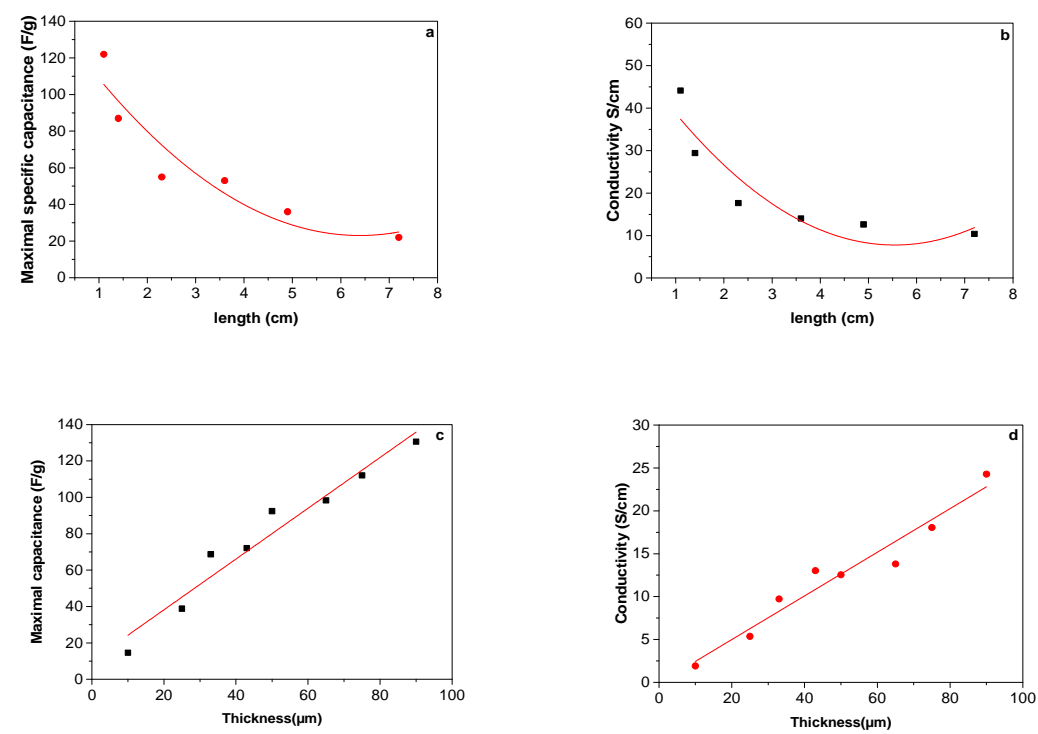

Figure 9: Effect of length and thickness of the hybrid film on electrical conductivity and the maximal capacitance measured at $50 \mathrm{~Hz}$ and $0.3 \mathrm{~V}$. (a) and (c) $\mathrm{G}(60 \mathrm{wt} \%) / \mathrm{MWCNT}(40 \mathrm{wt} \%)$; (b) and (d) GO(60wt\%)/MWCNT (40\%). 
The effect of length and thickness can be understood by considering layer structures formed as illustrated as an equivalent capacitor circuit for the hybrid film. The stacked layers of the film can be considered as arrangement of massive series circuits. Each layer consists of sub capacitors that form a parallel circuit. The total capacitance will be calculated by summation of all these parallel sub capacitors in the film first and then the series capacitor all over the length. This can be expressed by the following equation.

$$
\mathrm{C}_{\mathrm{t}}=\sum_{1}^{\mathrm{j}}\left(\frac{1}{\sum_{1}^{\mathrm{i} 1} / \mathrm{C}_{\mathrm{ij}}}\right)
$$

$\mathrm{C}_{\mathrm{t}}$ is the total capacitance and $\mathrm{C}_{\mathrm{ij}}$ is the $\mathrm{ij}^{\text {th }}$ sub-capacitance. The experimental results are in a good agreement with equation. High value of a total capacitance is always observed in a thicker and shorter film when the length is fixed.

\section{SUMMARY}

Graphene (G) and graphene oxide (GO)/carbon nanotubes (CNTs) hybrid films were fabricated as high performance electrode materials by a simple water solution casting method with different contents of single-wall CNT (SWCNT), multi wall CNT (MWCNT) and multi wall CNT with hydroxyl group (MWCNT-OH). The films with MWCNTs showed a layered, interconnected and well entangled structure at nano-scale. With increasing CNT contents, the capacitance of the G/MWCNT and GO/MWCNT films raised almost linearly and their resistance reduced. G/SWCNT and GO/SWCNT films did not form layered structures leading to a very low capacitance. Nonlinear behaviour of the capacitance with voltage has been observed in the G/MWCNT and GO/MWCNT hybrid films. The results indicate that the length and thickness of the hybrid film have significant influences on the capacitance and conductivity. The capacitance and conductivity increases with increasing the thickness of the film and decreases with increasing the length. For the application of graphene/CNT hybrid films as electrodes, this character could be taken into account.

\section{ACKNOLEDGEMENTS}

We thank EPSRC (UK) for providing funding (EP/P505623) for part of this work 


\section{REFERENCES}

1. K. V. Emtsev, A. Bostwick, K. Horn, J. Jobst, G. L. Kellogg, L. Ley, J. L. McChesney, T. Ohta, S. A. Reshanov and J. Rohrl, Nat. Mater., 8, 203-207 (2008)

2. S. C. Xu, B. Y. Man, S. Z. Jiang, C. S. Chen, C. Yang, M. Liu, X. G. Gao, Z. C. Sun and C. Zhang, CrystEngComm, 15, 1840-1844 (2013)

3. V. Yong and H. T. Hahn, CrystEngComm, 2011, 13, 6933-6039 (2011)

4. X. Li, W. Cai, J. An, S. Kim, J. Nah, D. Yang, R. Piner, A. Velamakanni, I. Jung, E. Tutuc, S. K. Banerjee, L. Colombo and R. S. Ruoff, Science, 324, 1312-1314 (2009)

5. C. Xu, J. H. Lee, J. C. Lee, B. S. Kim, S. W. Hwang and D. Whang, CrystEngComm, 13, 6036-6039 (2011)

6. Y. Zhu, Z. Sun, Z. Yan, Z. Jin and J. M. Tour, ACS Nano, 5, 6472-6479 (2011)

7. A. Javey , J. Guo , Q. Wang , M. Lundstrom , H. Dai , Nature , 424 , 654 (2003)

8. T. Durkop, S. A. Getty, E. Cobas , M. S. Fuhrer, Nano Lett. 4 ,35 (2004)

9. K. S. Novoselov, A. K. Geim, S. V. Morozov, D. Jiang, Y. Zhang, S. V. Dubonos, I. V. Grigorieva , A. A. Firsov, Science 306, 666 (2004)

10. K. S. Novoselov, Z. Jiang, Y. Zhang, S. V. Morozov, H. L. Stormer, U. Zeitler, J. C. Maan, G. S. Boebinger, P. Kim , A. K. Geim , Science 315, 1379 (2007)

11. R. B. Sharma , D. J. Late, D. S. Joag, A. Govindaraj , C. N. R. Rao, Chem. Phys. Lett., 428 , 102 (2006)

12. Q. He, H. G. Sudibya, Z. Yin, S. Wu, H. Li, F. Boey, W. Huang, P. Chen, and H. Zhang, ACS Nano, 4, 3201-3208 (2010)

13. Y. Si and E. T. Samulski, "Exfoliated graphene separated by platinum nanoparticles," Chem. Mater., 20, 6792-6797, 2008.

14. E. Yoo, J. Kim, E. Hosono, H.-S. Zhou, T. Kudo, and I. Honma, Nano Lett., 8, 2277$2282(2008)$.

15. C. Wang, D. Li, C.O. Too, and G. G.Wallace, "Electrochemical properties of graphene paper electrodes used in lithium batteries," Chem. Mater., 21, 2604-2606, (2009)

16. Z. Yin, S.Wu, X. Zhou, X. Huang, Q. Zhang, F. Boey, and H. Zhang, "Electrochemical deposition of $\mathrm{ZnO}$ nanorods on transparent reduced graphene oxide electrodes for hybrid solar cells," Small, 6, 307-312 (2010)

17. S. Park, J. An, J. W. Suk, and R. S. Ruoff, "Graphene-based actuators," Small, 6, 210-212 (2010) 
18. M. D. Stoller, S. Park, Y. Zhu, J. An, and R. S. Ruoff, “Graphene-based ultracapacitors," Nano Lett., 8, 3498-3502 (2008)

19. X. Zhao, H. Tian, M. Zhu,K. Tian, J. J. Wang, F.Kang, and R. A. Outlaw, “Carbon nanosheets as the electrode material in supercapacitors," J. Power Sources, 194, $1208-1212(2009)$

20. Y. Wang, Z. Shi, Y. Huang, Y. Ma, C. Wang, M. Chen, and Y. Chen, "Supercapacitor devices based on graphene materials," J. Phys. Chem., 113, 13103-13107 (2009)

21. S. R. C. Vivekchand, C. S. Rout, K. S. Subrahmanyam, A. Govindaraj, and C. N. R. Rao, "Graphene-based electrochemical supercapacitors," J. Chem. Sci., 120, 9-13, (2008)

22. V. Jousseaume, J. Cuzzocrea , N. Bernier, V. T. Renard, Appl. Phys. Lett. 98 , $123103(2011)$

23. T. Pei , H. Xu , Z. Zhang, Z. Wang, Y. Liu , Y. Li, S. Wang, L. -M. Peng, Appl. Phys. Lett. 99 , 113102 (2011)

24. D. H. Lee , J. E. Kim , T. H. Han , J. W. Hwang, S. Jeon, S. -Y. Choi , S. H. Hong, W. J. Lee, R. S. Ruoff, S. O. Kim , Adv. Mater. 22, 1247 (2010)

25. S. H. Kim, W. Song, M. W. Jung, M.-A. Kang, K. Kim, S.-J. Chang, S. S. Lee, J. Lim, J. Hwang, S. Myung, and K.-S. An, Adv. Mater., 26, pp. 4247-52, (2014)

26. L. L. Zhang, R. Zhou, and X. S. Zhao, J. Mater. Chem., 20, 5983-5992 (2010)

27. W. Lv, D.-M. Tang, Y.-B. He, C.-H. You, Z.-Q. Shi, X.-.C Chen, C.-M. Chen, P.-X. Hou, C. Liu, and Q.-H. Yang, ACS Nano, 3, 3730-3736, (2009)

28. A. V. Murugan, T. Muraliganth, and A. Manthiram, Chem. Mater., 21, 5004-5006 (2009)

29. K. Zhang, L. L. Zhang, X. S. Zhao, and J. Wu, "Graphene/polyaniline nanofiber composites as supercapacitor electrodes," Chem. Mater., 22, 1392-1401(2010)

30. D.-W. Wang, F. Li, Z.-S. Wu, W. Ren, and H.-M. Cheng, Electrochem. Commun., 11, $1729-1732(2009)$

31. Y. Chen, X. Zhang, P. Yu, and Y. Ma, J. Power Sources, 195, 3031-3035 (2010)

32. D.-W.Wang, F. Li, J. Zhao,WRen, Z.-G. Chen, J. Tan, Z.-S.Wu, I.Gentle, G. Q. Lu, and H.-M. Cheng, ACS Nano, 3, 1745-1752 (2009)

33. D. Yu and L. Dai, J. Phys. Chem. Lett., 1, 467-470 (2010)

34. J. Yan, T. Wei, Z. Fan, W. Qian, M. Zhang, X. Shen, and F. Wei, J. Power Sources, 195, 3041-3045 )2010) 
35. G. G. Wallace, J. Chen, D. Li, S. E. Moulton, and J. M. Razal, J. Mater. Chem., 20, 3553-3562 (2010)

36. H.-K. Jeong, M. Jin, E. J. Ra, K. Y. Sheem, G. H. Han, S. Arepalli, and Y. H. Lee, ACS Nano, 4, 1162-1166 (2010)

37. H. Wang, Q. Hao, X. Yang, L. Lu, and X. Wang, 11, 1158-1161 (2009)

38. C.-P. Tien and H. Teng, J. Power Sources, 195, 2414-2418 (2010)

39. X. Zhou, X. Huang, X. Qi, S. Wu, C. Xue, F. Boey, Q. Yan, P. Chen, and H. Zhang, J. Phys. Chem. C, 113, 10842-10846 (2009)

40. I. N. Kholmanov, S. H. Domingues, H. Chou, X. Wang, C. Tan, J. Kim, H. Li, R. Piner, A. J. G. Zarbin, and R. S. Ruoff, 2, 1811-1816 (2013)

41. C. Wang, Y. Hu, C. M. Lieber and S. Sun, J. Am. Chem. Soc., 2008, 130, 8902-8903.

42. S. De, T. M. Higgins, P. E. Lyons, E. M. Doherty, P. N. Nirmalraj, W. J. Blau, J. J. Boland and J. N. Coleman, ACS Nano, 3, 1767-1774 (2009)

43. D. Wang and C. M. Lieber, Nat. Mater. 2, 355-356 (2003)

44. L. Yang, T. Zhang, H. Zhou, S. C. Price, B. J. Wiley and W. You, ACS Appl. Mater. Interfaces, 3, 4075-4084 (2011)

45. W. Hu, X. Niu, L. Li, S. Yun, Z. Yu and Q. Pei, Nanotechnology, 23, 344002 (2012)

46. S. Xu, B. Man, S. Jiang, M. Liu, C. Yang, C. Chen, and C. Zhang, CrystEngComm, $16,3532(2014)$

47. S. Stankovich, R. D. Piner, X. Chen, N. Wu, S. T. Nguyen, R. S. Ruoff, J. Mater. Chem. 16, 155 (2006)

48. W. Zhao, M. Fang, F. Wu, H. Wu, L. Wang, G. Chen, J Mater Chem 20,5817(2010)

49. W.S. Hummers, R.E. Hoffman, J Am Chem Sco 80,1339 (1958) 